\title{
Local Flame Attachment and Heat Fluxes in Wind-Driven Line Fires
}

\author{
Wei Tang*, Colin H. Miller, Michael J. Gollner* \\ University of Maryland College Park, College Park, Department of Fire Protection Engineering, 3106 J.M. Patterson \\ Bldg., College Park, MD 20742, United States
}

Corresponding Author 1: Michael J. Gollner

Department of Fire Protection Engineering

University of Maryland, College Park

3106 J.M. Patterson Bldg.

College Park, MD 20742, U.S.A.

Email: mgollner@umd.edu

Phone: +1 (301) 405-6667

Fax: +1 (301) 405-9383

Corresponding Author 2: Wei Tang

Department of Fire Protection Engineering

University of Maryland, College Park

3106 J.M. Patterson Bldg.

College Park, MD 20742, U.S.A.

Email: wtang125@umd.edu

(C) 2016. This manuscript version is made available under the Elsevier user license http://www.elsevier.com/open-access/userlicense/1.0/ 
Phone: +1 (202) 802-7460

Fax: +1 (301) 405-9383

Preferred Colloquium: Fire Research

Paper Length: words 5228 (971 available, Method 1)

Text $=2894$ words

Equations $=190$ words

Equation $1=(1$ lines +2 blank $) * 7.6$ words $/$ line $* 1=22.8$

Equation $2=(2$ lines +2 blank $) * 7.6$ words $/$ line $* 1=30.4$

Equation $3=(3$ lines +2 blank $) * 7.6$ words $/$ line $* 1=38$

Equation $4=(1$ lines +2 blank $) * 7.6$ words $/$ line $* 1=22.8$

Equation $5=(1$ lines +2 blank $) * 7.6$ words $/$ line $* 1=22.8$

Equation $6=(2$ lines +2 blank $) * 7.6$ words $/$ line $* 1=30.4$

Equation $7=(1$ lines +2 blank $) * 7.6$ words $/$ line $* 1=22.8$

References $=437$ words

$(23+2) * 2.3 * 7.6=437$

Tables $=91$ words 
Table $1=(10+2) * 7.6 * 1=91$

Figures and Captions $=1616.3$ words

Figure $1(64+10) * 2.2 * 1+4=166.8$

Figure $2(50.3+10) * 2.2 * 1+15=147.66$

Figure $3(160.9+10) * 2.2 * 2+40=791.96$

Figure $4(50.3+10) * 2.2 * 1+9=141.66$

Figure $5(68.5+10) * 2.2 * 1+54=226.7$

Figure $6(50.3+10) * 2.2 * 1+9=141.66$

Abstract Length: 246 words (54 available)

Color Reproduction: Not Required

Keywords: Heat flux, flame attachment, wind-driven flame spread, wildland fire, concurrent spread 


\title{
Local Flame Attachment and Heat Fluxes in Wind-Driven Line Fires
}

\author{
Wei Tang, Colin H. Miller, Michael J. Gollner \\ University of Maryland College Park, College Park, Department of Fire Protection Engineering, 3106 J.M. Patterson Bldg., \\ College Park, MD 20742, United States
}

\begin{abstract}
A detailed experimental investigation of turbulent diffusion flames under forced flow was conducted to study local heat fluxes to a nearly adiabatic surface downstream of a gaseous line burner. A variety of ambient wind velocities and fuel flow rates were employed to study different fire scenarios modeling the dynamics of wind-driven fire spread as found in wildland, mine or tunnel fires. The downstream heat flux distribution was correlated as a piecewise function with the Richardson number in two regimes, the first with higher heat fluxes, where the flame remained attached the downstream surface (attached region) and the second with a steeper decay of heat fluxes (plume region). Analysis of the heat flux distribution revealed that local heat fluxes roughly reach a maximum where the Richardson number equaled unity. This was thought to be a good marker of the regime where the flame detaches from the surface, e.g. where buoyancy from the flame overcomes inertial forces from the oncoming flow. This observation was further corroborated by analysis of side-view images of the flame, which showed the attachment location was linearly correlated with the location where the Richardson number equaled unity. The results from this study suggest that local heat flux values reach a maximum at the transition between a momentum-dominated (attached, wind-driven) to buoyancydominated (plume or fire) regime in forced flow scenarios. The results have interesting implications to the problem of flame attachment, which is known to accelerate fire spread in both inclined and wind-driven fire scenarios.
\end{abstract}


Keywords: Heat flux, flame attachment, wind-driven flame spread, wildland fire, concurrent spread

\section{Introduction}

The heat flux downstream from a burning fire has often been of interest to fire safety researchers because downstream heating is known to govern a fire's rate of spread [1]. The rate of flame spread depends on this heat flux to unburned fuel ahead of the burning (pyrolysis) region, $x_{p}$,

the distribution of this heat flux (as it may not be constant), $\dot{q}_{f}^{\prime \prime}(x)$, and the length of this region (nominally the flame minus pyrolysis length, $x_{f}-x_{p}$ ). While these features have been somewhat well studied in upward configurations over a vertical wall where buoyancy and spread occur in the same direction [2-4], much less information is available in wind-driven configurations where they are both significant and perpendicular [5]. These configurations are vitally important to understand the dynamics of spreading wildland fires [6], tunnel fires [7] and mine fires [8]. While some of these configurations occur in a closed (bounded) configuration, the dynamics of the process are still relatively translatable except in the regime where the top surface begins to influence the flame.

Spreading fires are difficult to study because the flame moves as a function of time, often accelerating, making it difficult to measure important features such as downstream heat fluxes. Experiments with real fuels are also complicated because external conditions such as ambient winds or slope not only affect the spread rate, but also the burning rate of the fuel, modifying the downstream flame length and heat fluxes. In order to decouple and simplify the problem, a gas burner is often used to represent the pyrolyzing region, $x_{p}$ remaining stationary with a fixed burning rate over time. This technique has been used before to study flame spread over fabrics [9] 
and sloped surfaces $[10,11]$, however little information is available in the literature for a forcedflow configuration [8]. Certainly, a forced-flow configuration will be somewhat more complicated because it is difficult to even define $x_{f}$, as the flame lifts from the surface but technically is present above the fuel. The steady gas-burner configuration will enable heat fluxes from the flame to a nearly-adiabatic downstream surface to be measured over long times, collecting average information of the flame behavior and how it would affect flame spread.

\section{Literature Review}

Heat fluxes from both spreading and stationary fires in upward [2-4], sloped [10, 11] and forcedflow configurations [12-14] have been measured in the past using various techniques. Because the flame spread process is incredibly complex, most formulations simplify the spatial dependence of the heat flux ahead of $x_{p}$ as a constant [15-16] or as a power-law or exponential function of downstream distance [17]. Markstein and de Ris fit this dependence for upward and inclined line burners to simulate flame spread over fabric as a decaying power law function, here represented as

$$
\dot{q}_{f}^{\prime \prime}(x)=A\left(x / x_{p}\right)^{n}
$$

where $x$ is the downstream distance from the upstream edge of the fuel, $x_{p}$ is the pyrolysis length and $A$ and $n$ constants fit to the data [9]. In a study by Gollner $e t$ al., the exponent $n$ was found to vary between -2 to -7 for different inclined angles of PMMA [17], but no values were found for forced-flow flames.

What is clear from previous studies is that when an external ambient flow is applied over a fire, natural convection from buoyancy and forced convection from the wind will both play a role in 
the shape of the flame and, consequently, the heat flux from the flame to surrounding unignited fuels. As the velocity of the wind is increased, a considerable portion of the heat flux from the flame will be received by the downstream surface because the flame will "tilt" or "attach" closer to that surface, increasing both convective heat transfer due to its closer location and radiative heat transfer due to its improved view factor. While studies have described flame attachment on inclined surfaces $[10,11]$, there are few works addressing a wind-driven horizontal configuration $[8,18,19]$. Apte et al. did study wind-driven flame spread in an enclosed tunnel over PMMA, clearly delimitating attached and plume flow regimes, however they were not able to draw larger conclusions as the flame spread and accelerated as a function of time [8]. Similarities can be seen, however, in combined forced and natural convection over a hot plate as our small-scale experiments are mostly dominated by convective heat transfer [20-22]. For these problems, the Grashof, $G r_{x}=g \beta\left(T_{h}-T_{\infty}\right) x^{3} / v^{2}$ and Reynolds $\operatorname{Re}_{x}=U x / v$ numbers have been used to described both heat transfer and transition, where $T_{h}$ is the hot gas temperature, $T_{\infty}$ is the ambient temperature, $x$ is downstream distance along the plate, $g$ the acceleration due to gravity, $U$ the ambient velocity, $\beta$ the thermal expansion coefficient and $v$ the kinematic viscosity of the ambient air. For flow over a hot plate, the relative role of buoyancy and inertial forces have been described using a correlating parameter, $\mathrm{Gr}_{x} / \operatorname{Re}_{x}^{b}[22]$.

In this work, $b=2$ is chosen to describe the competition between forced and natural convection as a Richardson number,

$$
\mathrm{Ri}_{x}=\frac{G r_{x}}{\operatorname{Re}_{x}^{2}}=\frac{g \beta\left(T_{f}-T_{\infty}\right) x}{U^{2}}
$$


where instead of using $T_{h}$ we use the flame temperature, $T_{f}$. $\mathrm{Ri}_{x}$ can then be used to separate this competition under three regimes,

$$
\operatorname{Ri}_{x} \begin{cases}<0.1 & \text { forced convection controlled } \\ (0.1 \sim 10) & \text { mixed convection } \\ >10 & \text { natural convection controlled }\end{cases}
$$

The flame can then be thought of as dominated by inertial forces when $\mathrm{Ri}_{x}<0.1$, and by buoyant forces when $\mathrm{Ri}_{x}>10$ [21]. For fire, where strong buoyant forces due to both high temperatures and distributed heat release, as well as relatively low wind velocities occur, most problems lie in the mixed convection region. The details and implications of heat transfer modes in this mixed region $\left(0.1<\mathrm{Ri}_{x}<10\right)$ is of particular interest in our case, where the transition from an inertialdominant to buoyancy-dominant regime occurs.

In this paper, local total heat fluxes and gas-phase temperatures were measured over a semiadiabatic surface downstream of a thin gas burner made to represent a moving fire front. Analysis of this data has shown a clear correlation between the local total heat flux and the local Richardson number, with both the maximum heat flux and the visible transition between an attached flame and a more plume-like flow occurring near $\mathrm{Ri}_{x}=1$. A piece-wise function is then proposed to correlate the local heat flux distribution based on a local $\mathrm{Ri}_{x}$.

\section{Experimental Approach}

Figure 1 shows the experimental setup, which consists of a laminar blower, insulation board which acts as our semi-adiabatic surface with holes drilled through for insertion of a heat flux gauge, a sand burner connected to a propane tank, and a side-view camera. External winds were generated over the experimental setup using a unique laminar blower where a centrifugal fan was 
used to pressurize a large plenum followed by a series of reducing section with fine screens and honeycombs before it reaches the tunnel exit [23]. Wind velocities were carefully characterized using a hot-wire anemometer placed at the center of the cross-section, varying from 0.8 to 2.5 $\mathrm{m} / \mathrm{s}$ depending on the settings, with turbulent intensities repeatability controlled below $2 \%$.

[Figure 1 About Here]

The test section was located immediately following the tunnel exit and included a $25 \times 5 \times 8.5 \mathrm{~cm}^{3}$ gas burner, consisting of a large sand-filled section over a fine mesh to mix and evenly distribute propane gas over the simulated pyrolysis region. The burner length and width were selected to ensure a nearly-planar flame is maintained. Preliminary experiments with and without sidewalls showed that centerline measurements were not significantly affected by side air entrainment. The fuel flow rate was adjusted to provide simulated fire sizes of $6.3,7.9$ and $9.5 \mathrm{~kW}$ assuming complete combustion of propane $\left(\Delta H_{C}=46.4 \mathrm{MJ} / \mathrm{kg}\right)$.

A water-cooled Vatell total heat flux gauge (model HFM 1000-0), with a measurement range from $0-100 \mathrm{~kW} / \mathrm{m}^{2}$ and a response rate of $1 \mathrm{kHz}$, was inserted into pre-drilled holes and kept flush with surrounding insulation board to measure the total heat flux received by the surface downstream of the burner. The heat flux gauge was calibrated through a NIST-traceable method using a radiant cone heater. Because the heat-flux gauge surface has a known emissivity, this method works well against a known incident heat flux gauge, with calibration results showing a measured uncertainty less than $\pm 3 \%$. Heat fluxes were averaged over $200 \mathrm{~s}$ for each test point. The spacing between adjacent holes on the insulation board for the heat flux gauge was $5.5 \mathrm{~cm}$ measuring up to $33 \mathrm{~cm}$ downstream. The first measurement point could only start as close as 5.5 $\mathrm{cm}$ away from the trailing edge of the burner due to the configuration of the burner and gauge water-cooling system. 


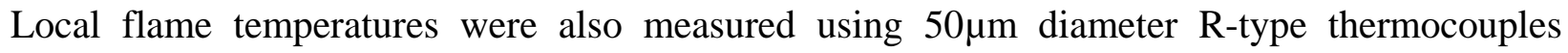
traversed on an $\mathrm{X}-\mathrm{Y}$ unislide from the surface of the heat flux gauge to the thermal boundary layer above the flame. Voltage signals from the thermocouples were acquired, conditioned and digitized through a National Instruments NI 9214, which is a 24-bit high density 16-channel thermocouple input module, averaged at each point for $60 \mathrm{~s}$. A radiation correction was applied to all temperature data, based on [5]. All tests were repeated 3 times to ensure repeatability. Table 1 shows the experimental conditions used in our tests.

Table 1. Experimental conditions used in tests

\begin{tabular}{cccc}
\hline Fire size $(\mathrm{kW})$ & Wind velocity $(\mathrm{m} / \mathrm{s})$ & $\begin{array}{c}\text { Downstream heat } \\
\text { flux locations }(\mathrm{cm})\end{array}$ & $\begin{array}{c}\text { Thermocouple locations } \\
\text { above the surface }(\mathrm{mm})\end{array}$ \\
\hline 6.3 & 0.87 & 5.5 & 0 \\
7.9 & 1.14 & 11 & 2 \\
9.5 & 1.37 & 16.5 & 4 \\
& 1.62 & 22 & 6 \\
& 1.91 & 27.5 & $\ldots$ \\
& 2.14 & 33 & 20 \\
& 2.45 & & 20 \\
\hline
\end{tabular}

A side-view camera was also used to capture flame images. Pictures are averaged, a threshold applied to distinguish flame vs. no flame and the flame attachment length on the downstream surface determined as the distance between the burner trailing edge to the location where the distance between the flame and the surface reaches $5 \mathrm{~mm}$ using a custom MATLAB script.

\section{Total Heat Flux Distribution}

Figure 2 shows the total heat flux distribution measured downstream of the gas burner under low $(0.87 \mathrm{~m} / \mathrm{s})$ and high $(2.14 \mathrm{~m} / \mathrm{s})$ ambient velocities for three different fire sizes. The downstream 
distance $L$ is normalized by the burner hydraulic diameter $D_{H}$ to form a normalized downstream location,

$$
L^{*}=L / D_{H}
$$

As can be seen in the two inserted side-view images, increased ambient velocities causes the flame to both lengthen and attach to the downstream surface. With low velocities, buoyancy dominates the flame shape and only a small portion of the flame attaches to the surface ahead of the burner. Because the nearest heat flux gauge is located $5.5 \mathrm{~cm}$ from the burner edge, the peak heat flux, which we later show occurs at this transition point, is not picked up, instead only resolving the downstream decaying heat flux profile in the thermal plume, where the flame has already lifted off from the surface. This is seen in Fig. 2 as the heat flux decays from approximately $10 \mathrm{~kW} / \mathrm{m}^{2}$ to 0 , following a power-law decay like Eq. 1 . The fitted constants $A$ and $n$ are shown for each test. Unlike previous results for upward or inclined flame spread, where the exponent, $n$ varied from -2 to -7 , here the exponent was closest to -1 for low velocities. This corresponds to a heat flux value roughly inversely proportional to the downstream distance.

On the other hand, when the wind velocity is high enough, the flame starts to transition from a buoyancy-dominated to a momentum-dominated regime, remaining attached to the downstream surface for considerably longer distances. This momentum-dominated regime can also be seen in Fig. 2, where the heat flux to the downstream surface first increases to a peak value, then decreases with downstream distance. This makes sense for these smaller, convectivelydominated flames where the location of closest attachment occurs at a certain distance downstream of the burner, followed by a decay in the remaining attached flame. This work will 
be focused on finding the location where this heat flux value reaches its maximum and the implications of this location, as it may indicate transition from a momentum to buoyancydominant regime.

[Figure 2 About Here]

\section{Analysis of Local Natural and Forced Convection Regimes}

An analysis of the local Richardson number, $\mathrm{Ri}_{x}$ was performed for the aforementioned fire cases. It is found that $\mathrm{Ri}_{x}$ will undergo a transition as the flame grows and spreads downstream. When the flame starts at the burner leading edge, $\mathrm{Ri}_{x}$ is small $\left(\mathrm{Ri}_{x}<1\right)$ as $\mathrm{Gr}_{x}$ is smaller than $\mathrm{Re}_{x}$, and the flame is forced to the surface. With continued downstream distance and heat-release from the flame, the buoyant force increases until it equals the forward momentum forces $\left(\mathrm{Ri}_{x}=1\right)$. After this point, the flame becomes buoyantly dominated and appears as an upward plume lifted away from the fuel surface. In Fig. 3, $\mathrm{Ri}_{x}$ and the heat flux to the surface are plotted against $L^{*}$ for two typical scenarios. In both scenarios shown (Fig. 3(a), Fig. 3(b)), the dimensionless location where $\mathrm{Ri}_{x}=1\left(L_{R_{x}=1}^{*}\right)$ and where the peak heat flux is observed $\left(L_{p e a k}^{*}\right)$ appear to be correlated.

Figure 3(c) then compares the correlation between $L_{R_{x}=1}^{*}$ and $L_{p e a k}^{*}$. As they are very nearly linearly correlated, it appears the location where the buoyant-inertial transition happens appears to also be the location of maximum heat flux. Note that there is a small deviation in the correlation between $L_{R_{x}=1}^{*}$ and $L_{\text {peak }}^{*}$ at the lowest wind velocity. This corresponds to the most buoyantly-dominant case, where a slightly different laminar-to-turbulent transition may be responsible for a deviation in the results.

[Figure 3 About Here] 
Looking back to images of the flame in forced and plume-like configurations in Fig. 2, the peak heat flux observed where $\mathrm{Ri}_{x}=1$ seems reasonable as the flame is observed to slightly curve before reaching an inflection point where it transitions to a plume-like configuration. This inflection point apparently causes significant flame attachment, which most likely results in very high convective heat fluxes (only total radiative plus convective measurements were conducted for this study). Figure 4 shows the dimensionless local total heat flux $\dot{q}_{f}^{*}$ plotted against the local $\mathrm{Ri}_{x}$, where $\dot{q}_{f}^{*}$ is

$$
\dot{q}_{f}^{*}=\dot{q}_{f}^{\prime \prime} /\left(\rho_{a} c_{p} \Delta T \sqrt{A g L}\right)
$$

with $\Delta T=T_{f}-T_{\infty}$ the difference between the flame and ambient temperature, $A=\Delta T /\left(T_{f}+T_{\infty}\right)$, $\sqrt{A g L}$ a characteristic buoyant velocity and $\rho_{a}$ and $c_{p}$ the density and specific heat capacity of air, respectively. This non-dimensional heat flux convention follows previous studies of mixed convection [20-22]. A piece-wise function,

$$
\dot{q}_{f}^{*}= \begin{cases}0.02 R i_{x}^{-0.25} & R i_{x}<1 \\ 0.03 R i_{x}^{-1.2} & R i_{x}>1\end{cases}
$$

was applied to correlate the local total heat flux to the downstream surface between two regimes, with a turning point occurring at $\mathrm{Ri}_{x}=1$. Equation (6) is shown as a solid line in Fig. 4, where it can be used to estimate the local total heat flux distribution on the downstream surface for a variety of ambient flows and fire sizes. The fact that the correlation matches the data relatively well also suggests that the parameter is appropriate to describe the processes occurring.

[Figure 4 About Here]

\section{Flame Attachment Length}


The flame attachment length along the downstream surface is an important parameter in assessing flame spread and should be correlated with heat fluxes at the surface for these convectively-dominated flames. The flame attachment length for each test was obtained by analyzing averaged side-view images. An intensity was applied to the images to give isocontours of the flame shape, shown for wind velocities with the same fire size in Fig. 5. The flame attachment length was then defined as the distance between the burner trailing edge to the downstream location where the flame contour is $5 \mathrm{~mm}$ from the downstream surface. This method is different than the 50\% threshold traditionally used to define flame heights, and for this configuration has low errors, estimated here by changing the threshold distance from the surface between 1, 2, 4, and $6 \mathrm{~mm}$. As the wind velocity is increased, the distance along which the flame attaches to the surface increases, but does so at a slower rate once the flame becomes nearly attached along the surface. This behavior will increase heat fluxes to the downstream surface which would, in turn, increase rates of flame spread.

\section{[Figure 5 About Here]}

The dimensionless flame attachment length, $L_{\text {attach }}^{*}$ was calculated by dividing the attachment length by the hydraulic diameter, $D_{H} . L_{\text {attach }}^{*}$ was then plotted against $L_{R i_{x}=1}^{*}$, the dimensionless location where $\mathrm{Ri}_{x}=1$. After plotting the values, shown in Fig. 6, a clear linear relationship was found between $L_{\text {attach }}^{*}$ and $L_{R_{x}=1}^{*}$,

$$
L_{\text {attach }}^{*}=1.55+0.5 L_{R i_{x}=1}^{*}
$$


Because different definitions for $L_{\text {attach }}^{*}$ could shift the values in Fig. 6 up or down, the attachment height $(5 \mathrm{~mm}$ ) was varied $\pm 15 \%$ to determine the error bars shown, which clearly have little effect on the relationship. Therefore, the flame attachment length appears to be directly correlated with the location of maximum heat flux, meaning that this location corresponds to where the transition between boundary layer to plume-like burning occurs.

\section{[Figure 6 About Here]}

\section{Conclusions}

The results from the present study show that the location where the maximum local heat flux received by downstream surface in a forced flow flame roughly matches the location where local $\mathrm{Ri}_{x}=1$. The dimensionless local total heat flux was correlated with downstream location in a piece-wise function based on the Richardson number, breaking up the correlation between the attached and plume regions. The visually-observed flame attachment length was also found for each test, and a linear correlation was found between this length and $\mathrm{Ri}_{\mathrm{x}}$. Information in this paper will be able to help estimate the downstream location where the most heat flux from a turbulent diffusion flame is received by an unburned surface, and also where the flame starts to rise up and eventually enter the plume region, thus shedding lights on the flame spread mechanisms downstream. More detailed knowledge of the local heat flux distribution, especially in terms of the radiation and convection fraction in the heat flux is still needed to further quantify the mechanisms of flame spread. To eventually connect these heat flux measurements to the development of practical flame spread models, additional work on solid-phase heating, pyrolysis and investigation at larger fire sizes will be needed.

\section{Acknowledgments}


The authors would like to acknowledge financial support for this work from the USDA Forest Service Missoula Fire Sciences Laboratory and National Fire Decision Support Center under collaborative agreement 13-CS-11221637-124 and the National Science Foundation under Grant No. 1331615. They would also like to thank Mark Finney, Arnaud Trouvé and Salman Verma for fruitful discussions and suggestions.

\section{References}

[1] A.C. Fernandez-Pello, T. Hirano, Combust. Sci. Technol., 32 (1983), pp. 1-31.

[2] Annamalai, K., M. Sibulkin. Combust. Sci. Technol., 19.5-6 (1979), pp. 167-183.

[3] Quintiere, J., Harkleroad, M., Hasemi, Y. Combust. Sci. Technol., 48(1986), pp.191-222.

[4] K. Saito, J.G. Quintiere, F.A. Williams, Int. Assoc. Fire Saf. Sci., (1985), pp. 75-86.

[5] A. V. Singh, M. J. Gollner, Combust. Flame, 162 (2015), pp. 2214-2230.

[6] Finney, M., Jack D., Jason M., Sara S., Michael G., Daniel G., Kozo S., Nelson A., Brittany A., Justin E.. Pro. Natl Acad Sci. 112, 32 (2015), pp. 9833-9838.

[7] Lönnermark, A., Haukur I., Fire Tech. 42.4 (2006), pp. 283-302.

[8] Apte, V. B., R.W. Bilger, A. R. Green, J. G. Quintiere. Combust. Flame 85 (1991), pp. 169184.

[9] Markstein, G., de Ris, J. Symp. (Intl.) Combust. 14 (1973), pp. 1085-1097.

[10] de Ris, J. L., Orloff, L., Ris, J. De, Orloff, L., de Ris, J. L., Orloff, L., Symp. (Intl) Combust. 15(1975), pp. 175-182.

[11] Atkinson, G. G. T., Drysdale, D. D., Wu, Y, Fire Saf. J., 25 (1995), pp. 141-158.

[12] A. C. Fernandez-Pello, Combust. Flame 36 (1979), pp. 63-78.

[13] Loh, H.T., A. C. Fernandez-Pello, 20 (1985).

[14] Shih, Y., and James S. T'ien, Combust. Theory Modelling 4 (2003), pp. 677-704. 
[15] J. Consalvi, Y. Pizzo, B. Porterie, Fire Saf. J. 43 (5) (2008), pp. 351-362.

[16] K. Tsai, J. Turnbull, G. Will, D. Drysdale, Fire Saf. Sci. 7 (2003), pp. 117-128.

[17] M.J. Gollner, X. Huang, J. Cobian, A.S. Rangwala, F.A. Williams, Proc. Combust. Inst., 34 (2013), pp. 2531-2538.

[18] A. C. Fernandez-Pello, Combust. Flame 36 (1979), pp. 63-78.

[19] L. Hu, J. Hu, S. Liu, W. Tang, X. Zhang, Proc. Combust. Inst., 35 (2015), pp. 2511-2518.

[20] N. Luo, W.G. Weng, M. Fu, Int. J. Heat Mass Transfer, 91 (2015), pp. 37-44.

[21] H. Imura, R.R. Gilpin, K.C. Cheng, J. Heat transfer, 100 (1978), pp. 429-434.

[22] H. F. Oztop, I. Dagtekin, Int. J. Heat Mass Transfer, 47 (2004), pp. 1761-1769.

[23] A. V. Singh, M. J. Gollner, AIAA Journal 54 (2) (2015), pp. 408-418. 


\section{Figure Captions}

Figure 1. Experimental setup.

Figure 2. Comparison of total heat flux measurements under different wind velocities and fire sizes.

Figure 3. Comparison of dimensionless downstream location at $\mathrm{Ri}_{x}=1$ with peak heat flux value Fig 4. Dimensionless local total heat flux with local $\mathrm{Ri}_{x}$.

Figure 5. Averaged flame images under different wind velocities show the attachment length $\left(L_{\text {attach }}\right)$ of the flame to the surface with scales. Regions between the two blue dashed lines represent the burner depth, while the red solid lines, which are $5 \mathrm{~mm}$ in height, represent the flame attachment length measured along the downstream surface.

Figure 6. $L_{R i_{x}=1}^{*}$ with dimensionless flame attachment length $L_{a t t a c h}^{*}$ 
Tables

Table 1. Experimental conditions used in tests 
figure 1

Therm ocouple

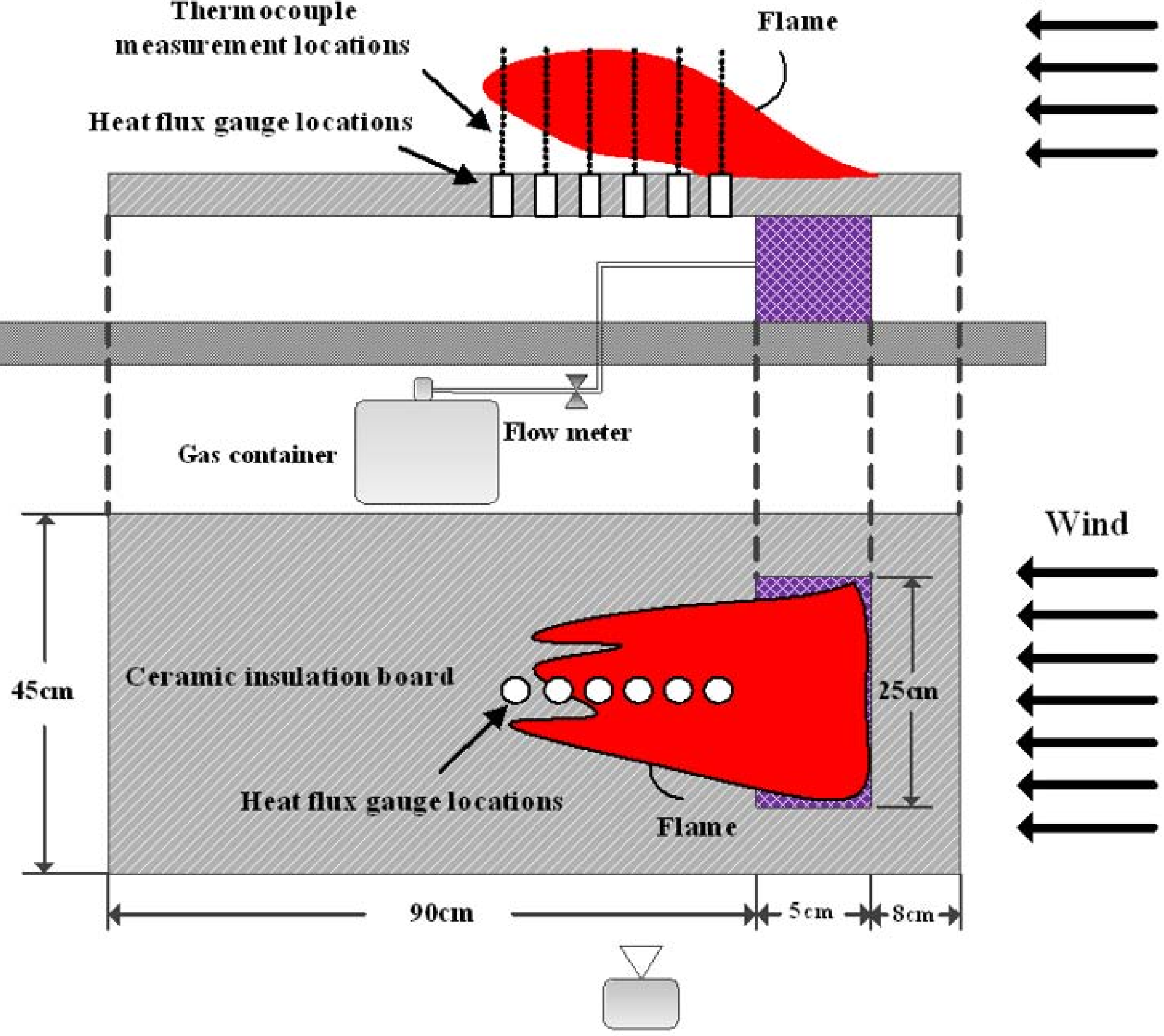

Side-view camera 
figure 2

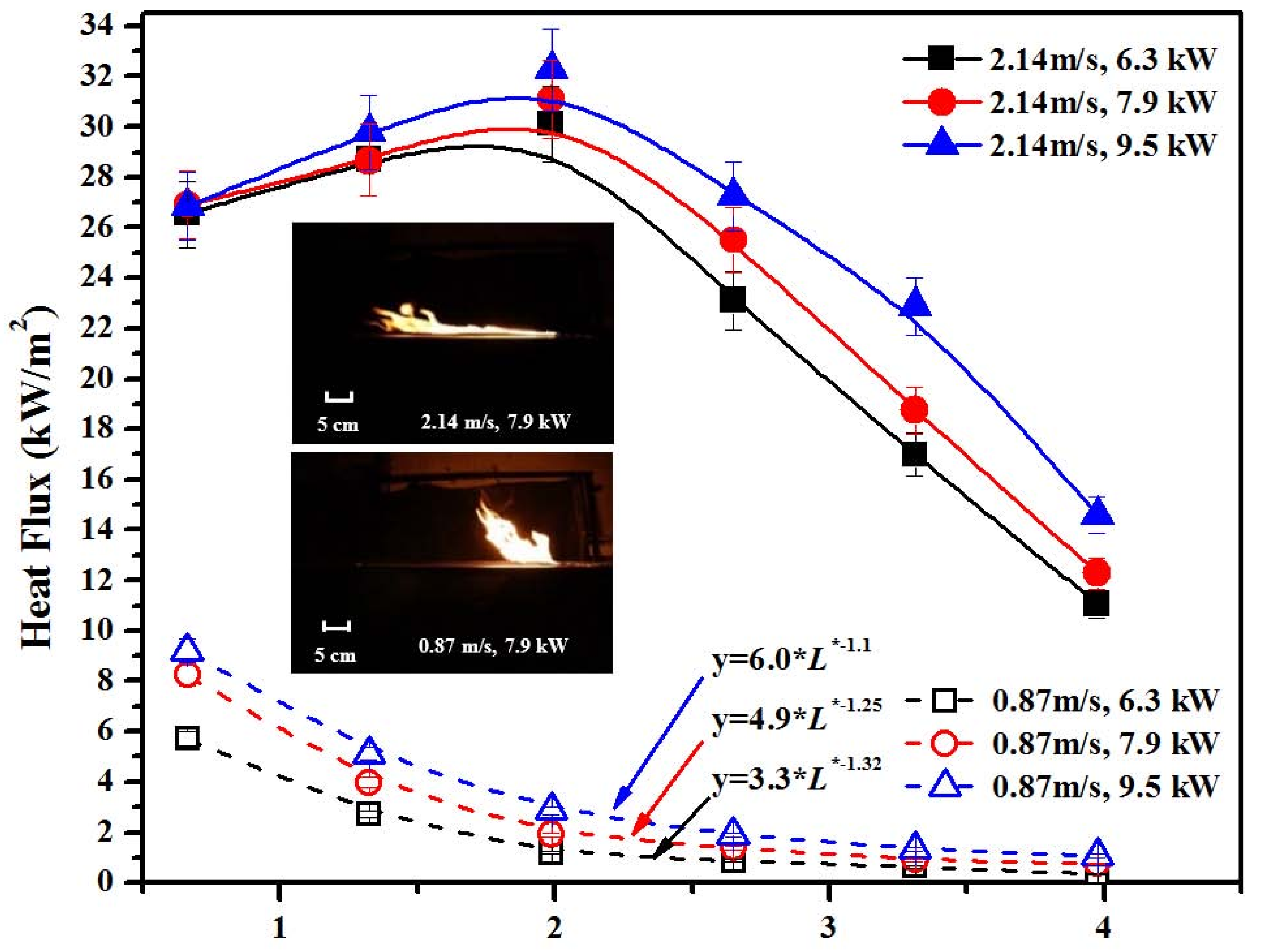

Dimensionless downstream location $L^{*}=L / D_{H}$ 
figure 3

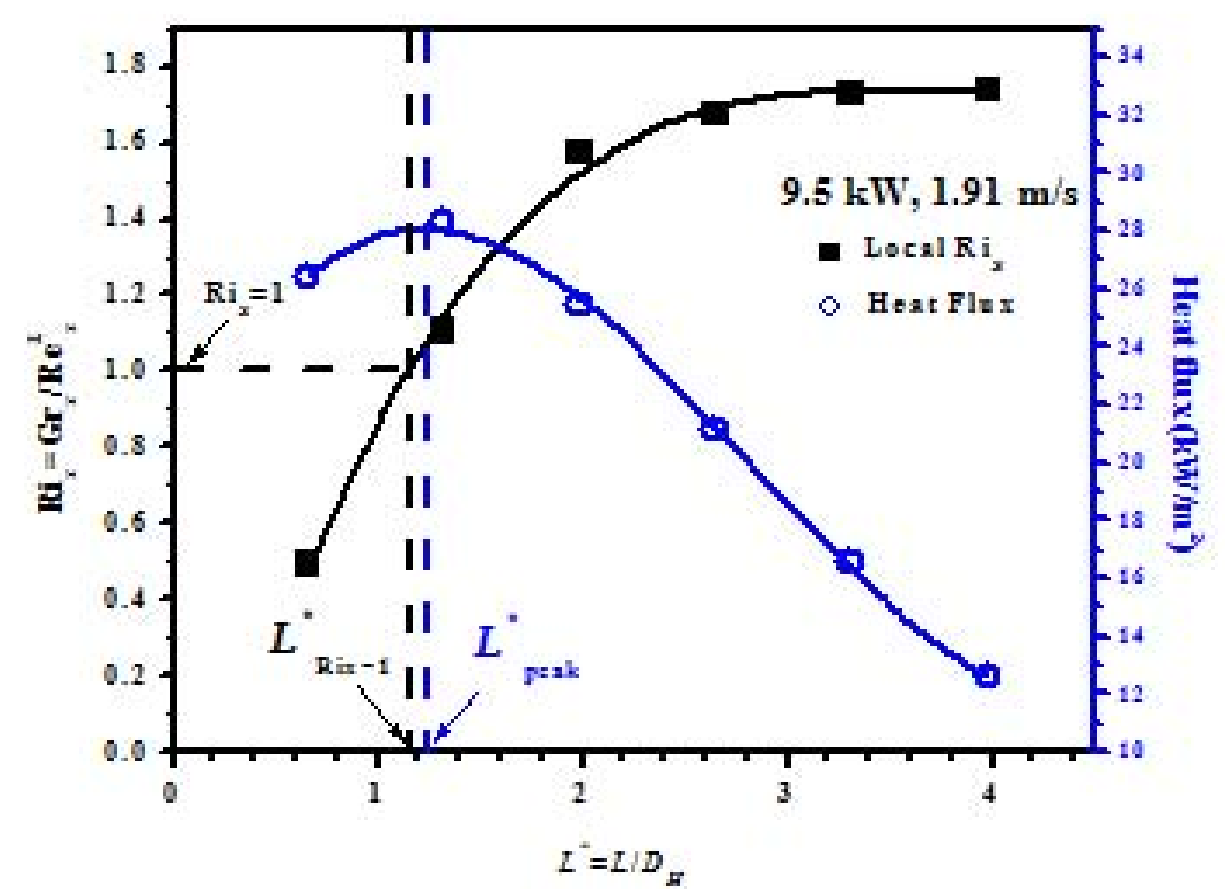

3(a). Local Rix with heat flux $(9.5 \mathrm{~kW}, 1.91 \mathrm{~m} / \mathrm{s})$

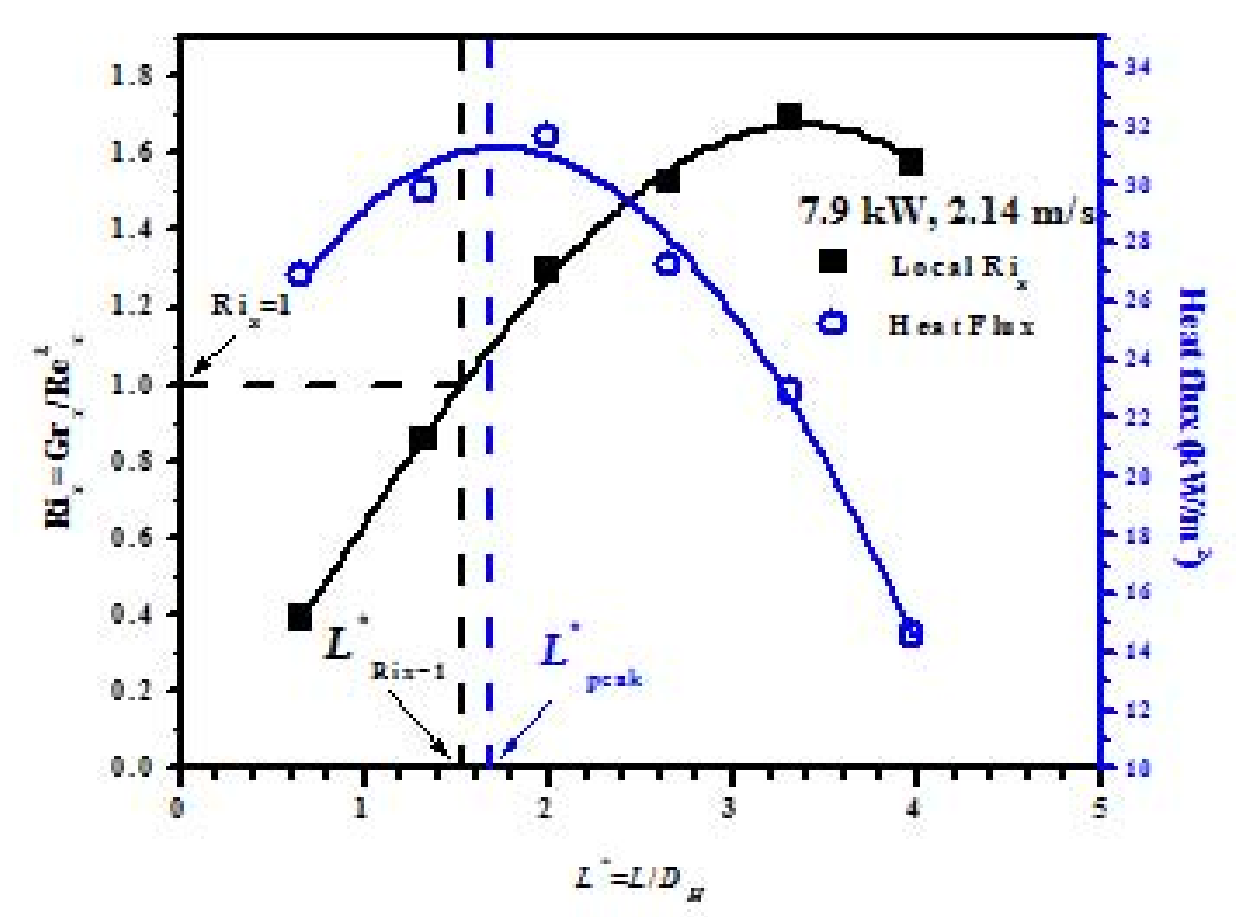

3(b). Local Rix with heat flux $(7.9 \mathrm{~kW}, 2.14 \mathrm{~m} / \mathrm{s})$

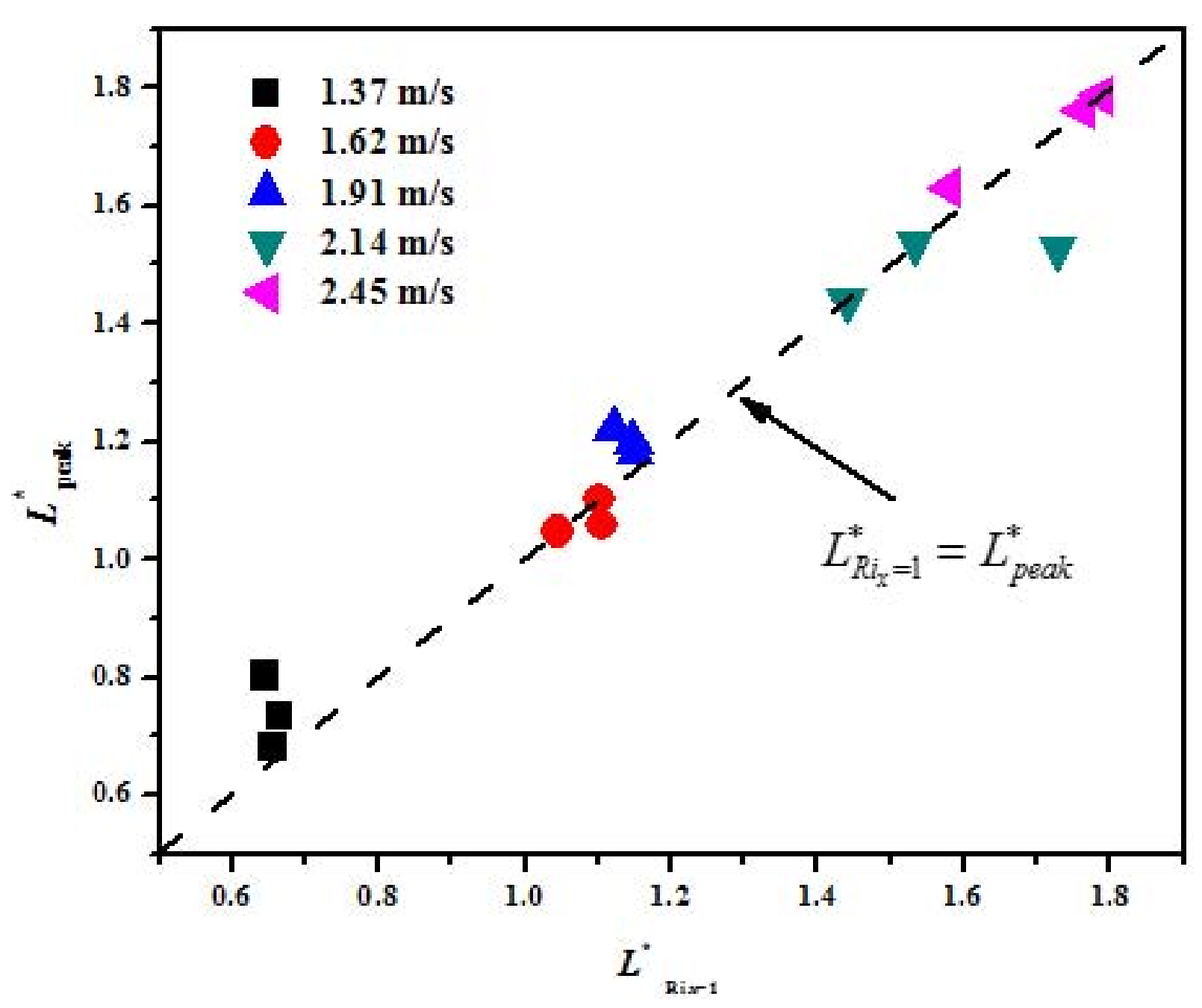

3(c). Dimensionless $L_{R_{x}=1}^{*}$ with $L_{\text {peak }}^{*}$ 
figure 4

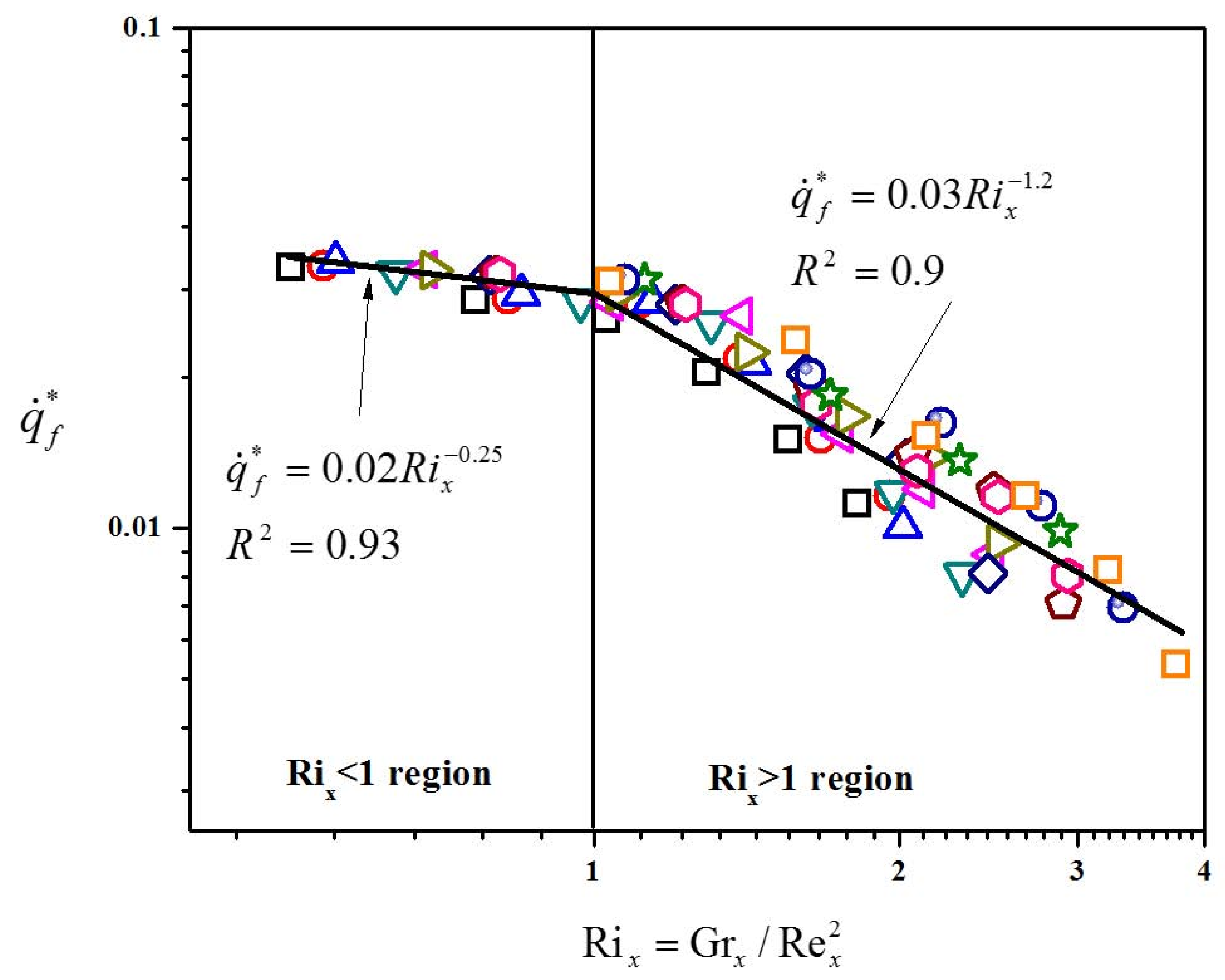




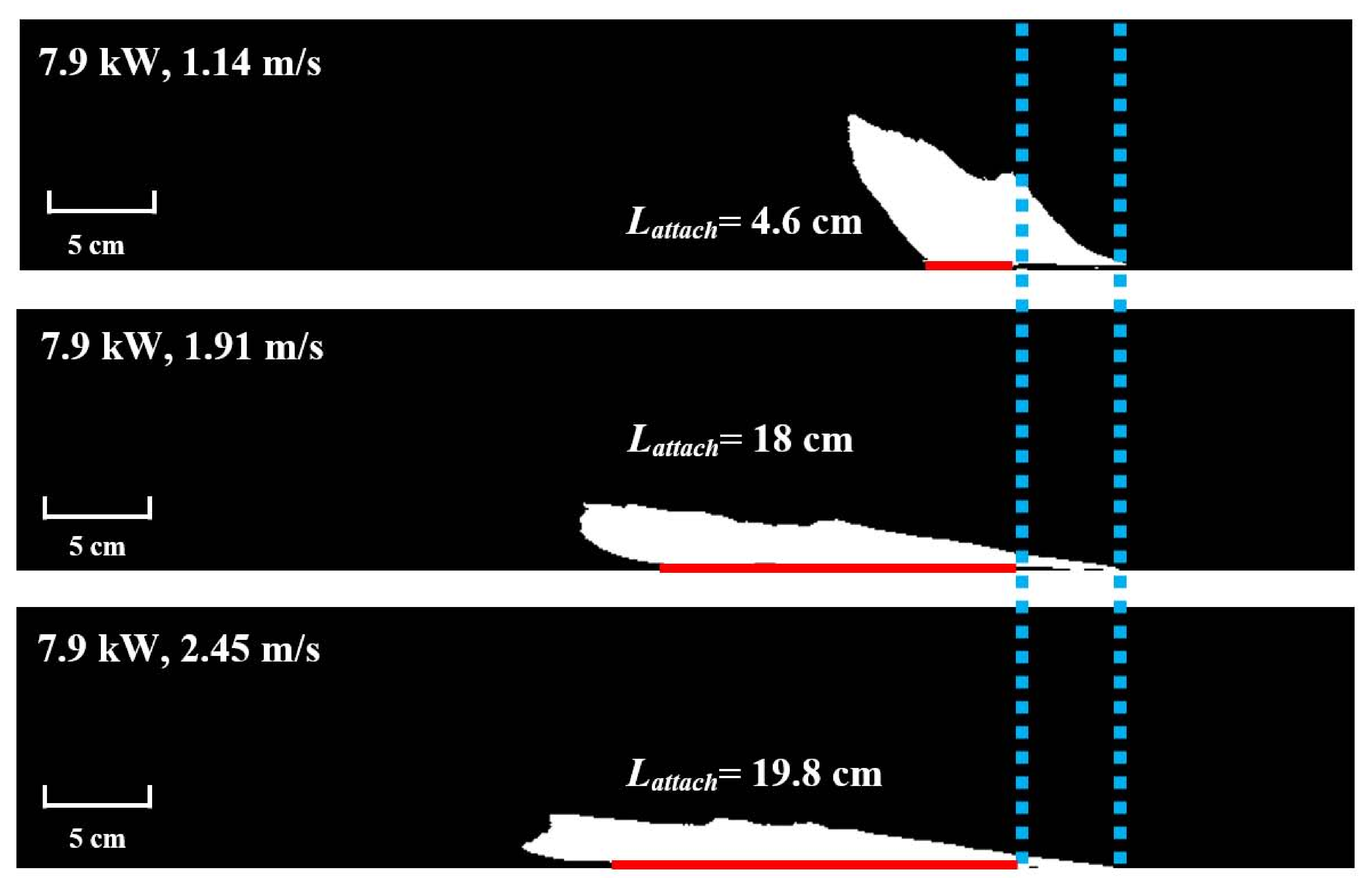


figure 6

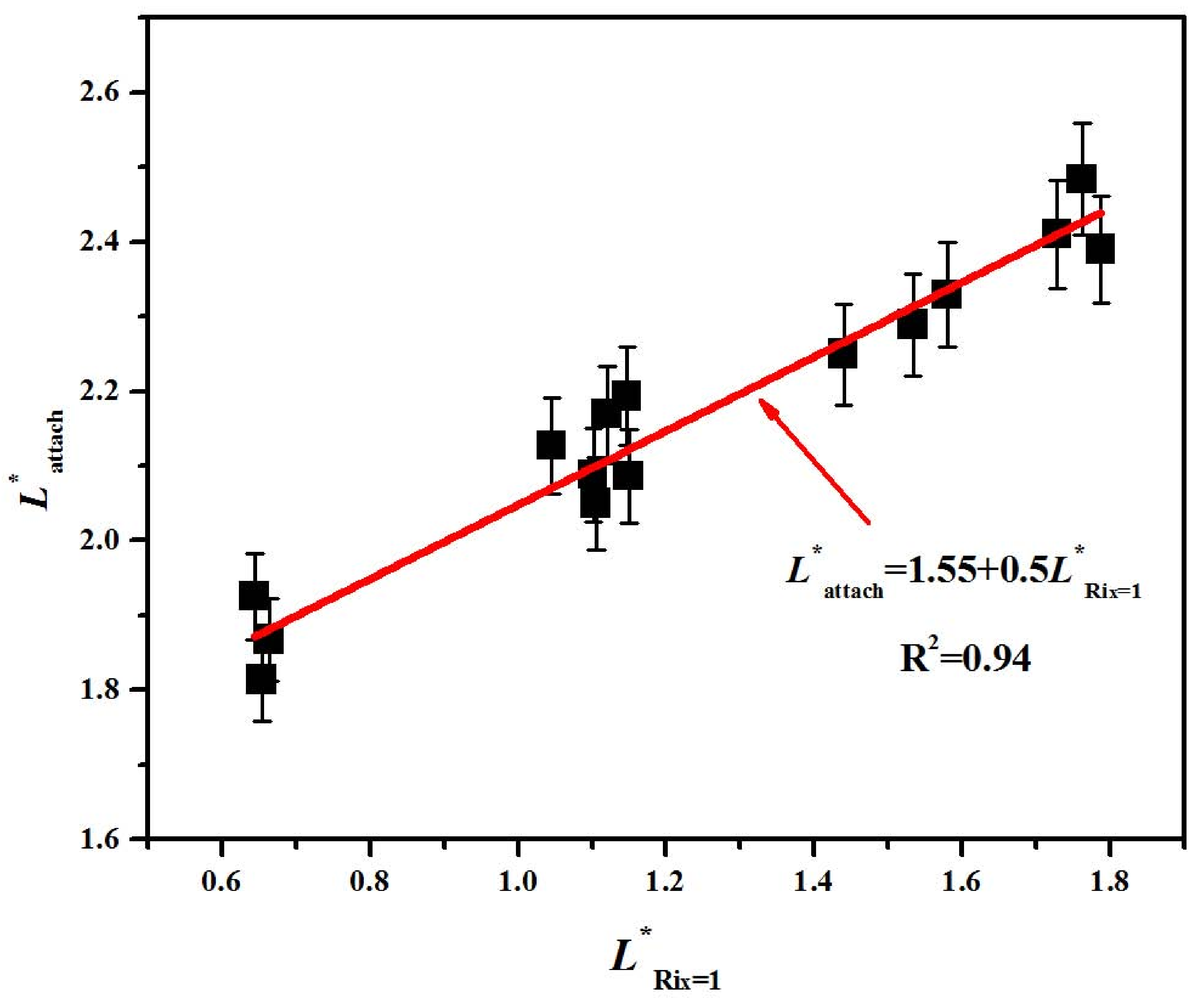

